\title{
DNA Repair Protein Expression and Oxidative/Nitrosative Stress in Ulcerative Colitis and Sporadic Colorectal Cancer
}

\author{
PAULA M. DE ANGELIS ${ }^{1}$, LINDA DORG $^{1}$, SEAN PHAM ${ }^{1}$ and SOLVEIG NORHEIM ANDERSEN ${ }^{2}$ \\ ${ }^{1}$ Department of Pathology, Oslo University Hospital, Oslo, Norway; \\ ${ }^{2}$ Department of Pathology, Akershus University Hospital, Lørenskog, Norway
}

\begin{abstract}
Background/Aim: Chronic inflammation generates large quantities of reactive oxygen and nitrogen species that damage DNA. DNA repair is important for cellular viability and genome integrity. Materials and Methods: Expression levels of the DNA repair proteins OGG1, XPA, MLH1, PARP1, and XRCC6, which function in base excision repair, nucleotide excision repair, mismatch repair, single-strand break repair and double-strand break repair, respectively, were assessed using immunohistochemistry in ulcerative colitis and sporadic colorectal cancer biopsies. Levels of oxidative/ nitrosative stress biomarkers were also assessed. Results: Ulcerative colitis and colorectal cancer lesions expressed significantly higher levels of all DNA repair proteins and oxidativel nitrosative stress biomarkers compared to normal colonic mucosa. Ulcerative colitis had the highest XPA and XRCC6 expression. Conclusion: Oxidative/nitrosative stress is prevalent in the colon of both diseases. Nucleotide excision repair and non-homologous endjoining double-strand break repair may be compromised in colorectal cancer, but not in ulcerative colitis.
\end{abstract}

Ulcerative colitis (UC) is a chronic inflammatory bowel disease characterized by continual inflammatory-induced destruction and regeneration of colonic mucosa, which can lead to dysplasia and cancer in certain patients. Chronic inflammation generates large quantities of reactive oxygen species (ROS) and reactive nitrogen species (RNS) that damage DNA via oxidation/deamination of DNA bases and lipids via peroxidation. Oxidative stress is characterized by an

This article is freely accessible online.

Correspondence to: Paula M. De Angelis, Ph.D., Department of Pathology, Oslo University Hospital-Rikshospitalet, Oslo, Norway. Tel: +47 23071505, e-mail: paulamdeangelis@gmail.com

Key Words: Ulcerative colitis, sporadic colorectal cancer, DNA repair proteins, oxidative/nitrosative stress biomarkers, 4-hydroxy2-nonenal, 3-nitrotyrosine, immunohistochemistry. imbalance in the prooxidant-antioxidant balance of a cell in favor of the former leading to ROS production and ROS interaction with other molecules in the cells, resulting in oxidative damage to DNA, proteins, and lipids $(1,2)$. Oxidative stress-induced DNA damage includes singlenucleobase lesions, strand breaks, and inter- and intra-strand crosslinks (3). Lipid peroxidation produces reactive aldehydes such as 4-hydroxy-2-nonenal (4-HNE) that react with DNA bases, leading to promutagenic exocyclic DNA adducts (4). Nitrosative stress, which is nitro-oxidative damage to proteins, is characterized by overproduction of nitric oxide and often by simultaneous production of superoxide anions, which results in the formation of peroxynitrite and other RNS (5). Tyrosine nitration/formation of 3-nitrotyrosine (3-NT) is a posttranslational protein modification resulting from RNS attack. 3-NT is considered to be a fairly specific marker of oxidative damage mediated by peroxynitrite and other RNS (5).

Base excision repair (BER), nucleotide excision repair (NER), and mismatch repair (MMR) are critical processes for the removal of accumulated mutations resulting from reactive oxygen and nitrogen species (RONS)-induced mutagenic damage. BER excises the base lesions caused by oxidation, deamination and alkylation. Nucleotide excision repair (NER) removes various helix-distorting lesions. Chronic inflammation also affects the mismatch repair pathway (MMR), which repairs replication errors such as base mismatches and small insertion/deletion loops (6). These types of repairs are important for cellular viability and genome integrity because they prevent the development of DNA single-strand breaks (SSBs) and double-strand breaks (DSBs). Single-strand break repair (SSBR) is important for the repair of SSBs that arise during BER of oxidized bases and abasic sites, or as a result of compromised activity of cellular enzymes such as DNA topoisomerase 1. The two major pathways for double-strand break repair (DSBR) are homologous recombination (HR) and non-homologous end joining (NHEJ). If DSBR is compromised or overwhelmed by RONS-induced DNA damage, genomic instability and cancer may occur. 
We recently reported that nuclear casein kinase and cyclindependent kinase substrate 1 (NUCKS1) expression decreased with increasing grades of UC dysplasia, and was lowest in sporadic colorectal carcinoma (CRC), whereas expression of $\mathrm{pH} 2 \mathrm{AX}$, a biomarker of DSB, increased with increasing grades of UC dysplasia, and was highest in sporadic CRC (7). It was suggested that the ability of NUCKS1 to repair DSB via homologous recombination may be compromised in high-grade UC dysplasia and CRC, but since NUCKS1 is also involved in inflammatory signaling, it was not possible to definitively conclude that this was the case. In the present work, we investigated the expression of specific DNA repair proteins that play important roles in the major DNA repair pathways: BER, NER, MMR, SSBR, and DSBR in the context of oxidative/nitrosative stress, in UC and CRC. The aim was to determine which, if any, DNA repair type was most prevalent in UC and CRC, and if the expression levels of DNA repair proteins could provide an indication about the capability of DNA repair activity. We also wanted to shed more light on the potential associations between oxidative/nitrosative stress and DNA damage/repair. The expression levels of OGG1, XPA, MLH1, PARP1, and XRCC6, which function in BER, NER, MMR, SSBR and DSBR, respectively, were assessed using immunohistochemistry. 4-hydroxynonenal (4-HNE) and 3nitrotyrosine (3-NT) were utilized as immunohistochemical biomarkers of oxidative/ nitrosative stress because they are very stable and thus suitable for analytical purposes $(5,8,9)$.

\section{Materials and Methods}

Ulcerative colitis biopsies. Colectomy specimens from thirteen patients with longstanding UC (10-30 years) resected at the Department of Surgery, Rikshospitalet, in the period 1985-1994 were utilized for this study. Fifty-seven previously-diagnosed UC biopsies (7) were available for immunohistochemical evaluations as formalin-fixed paraffin-embedded (FFPE) blocks. Histopathological diagnoses were performed according to the classification criteria described by Riddell et al. (10): negative for dysplasia (nondysplastic), indefinite for dysplasia (not possible to classify some epithelial changes as unequivocally positive or negative for dysplasia), and positive for dysplasia (unequivocally neoplastic, designated as low-grade or high-grade based on the degree of deviation from normal mucosa). Eighty percent of UC biopsies were negative for dysplasia, $4 \%$ were indefinite for dysplasia, $14 \%$ were positive for dysplasia, and $2 \%$ were colitis-associated cancer.

Sporadic colorectal cancer biopsies. Fifty-seven untreated sporadic colorectal tumor biopsies taken from patients who had undergone surgery during the period 1990-2001 at three regional hospitals (Ullevål University Hospital, Asker and Bærum County Hospital, and Vestfold County Hospital) were utilized for this study. Biopsies were available as FFPE archival material (tissue microarrays and whole sections). Preparation of the CRC tissue microarrays was described in a previous publication (11); each TMA contained 3 cores of tumor tissue from each patient and 2 cores of peritumoral normal mucosa (tissue cores were localized to $<5 \mathrm{~mm}$ from the cancer margin) or 2 cores of nonperitumoral normal mucosa (colectomy specimens without proximal cancer).

The cancer patient group consisted of 33 males and 24 females, with a mean age of 69 years. The Dukes' modified staging system was used to assess the degree of tumor spread. Of the 57 previouslydiagnosed CRC biopsies available for study, 3 were classified as Dukes' A, 31 as Dukes' B, 13 as Dukes' C, and 10 as Dukes' D. The majority of tumors had a histological classification of moderatelydifferentiated.

The Regional Ethics Committee (REC) of Southeast Norway approved the use of the ulcerative colitis and sporadic colorectal cancer biopsies for research purposes in this study. The REC number is 2015/628, the approved project is entitled "Cell biological investigations of neoplasms in the gastrointestinal tract", and the expiration date of approval is December 31, 2025. All patient information has been de-identified, and data generated from the study are stored on a secure hospital server in line with government regulations.

Immunohistochemistry for DNA repair proteins and RONS markers. Table I lists the DNA repair and oxidative/nitrosative stress antibodies and the working dilutions used in the present study. UC and CRC tissue sections were deparaffinized, rehydrated, and treated with $3 \%$ hydrogen peroxide for $30 \mathrm{~min}$ to block endogenous peroxidase, and then washed in double-distilled water 3 times for 5 min each. Heat-induced epitope retrieval (HIER) in citrate buffer $\mathrm{pH} 6$ was the antigen retrieval method used for all proteins/biomarkers. Slides were microwaved in citrate buffer and then allowed to cool at room temperature for $30 \mathrm{~min}$. Cooled slides were incubated in blocking solution (Tris-buffered saline containing $3 \%$ bovine serum albumin) for $30 \mathrm{~min}$ at room temperature. The primary antibodies listed in Table I were applied at the dilutions given in the table, and the slides were then incubated overnight at $4^{\circ} \mathrm{C}$ in a humidity chamber. Slides were rinsed 3 times in phosphatebuffered saline (PBS) for 5 min each time, and then incubated with ImmPress Anti-Mouse IgG Peroxidase (Vector Laboratories, Burlingame, CA, USA) for $30 \mathrm{~min}$ at room temperature. Slides were then washed 3 times in PBS for 5 min each time and then visualized with DAB Substrate Kit for Peroxidase (Vector Laboratories) for 10-15 min at room temperature. The reaction was stopped by placing slides in double-distilled water for $5 \mathrm{~min}$. The slides were counterstained with hematoxylin, washed, and mounted. Tissue sections where the primary antibody was replaced with blocking solution served as negative staining controls. Brown-stained nuclei were scored as positive.

Slide scanning and automatic counting of digital images. Stained slides were digitally scanned using a bright-field Pannoramic MIDI scanner with a $20 \times$ objective from 3DHistech (Budapest, Hungary). Digital image preparation (jpeg images) for counting was done using 3DHistech's Pannoramic Viewer software. Automatic counting was done directly on these images using QuPath open source software for digital image analysis (12). The QuPath algorithms facilitated the exclusion of infiltrating leucocytes and stromal cells; only epithelial cells were included for assessments of protein immunoreactivity (12, 13). A minimum of 1,500 epithelial cells was counted for each case. Individual DNA repair protein expression levels were defined as the percentage of positively-stained nuclei out of the total number of nuclei (negative and positive) counted. Oxidative/nitrosative stress biomarkers were evaluated for their staining intensity only, as 
Table I. DNA repair and oxidative/nitrosative stress antibodies used in this study.

\begin{tabular}{|c|c|c|c|c|}
\hline DNA repair pathway & $\begin{array}{l}\text { Protein or } \\
\text { marker }\end{array}$ & $\begin{array}{l}\text { Antibody/Manufacturer } \\
\text { catalog number }\end{array}$ & $\begin{array}{l}\text { Dilution of stock } \\
\text { antibody }\end{array}$ & $\begin{array}{l}\text { Antigen } \\
\text { retrieval }\end{array}$ \\
\hline BER & $\begin{array}{c}\text { OGG1 } \\
\text { (8-Oxoguanine glycosylase) }\end{array}$ & $\begin{array}{l}\text { Rabbit polyclonal/Invitrogen } \\
\text { PA5-86046 }\end{array}$ & $1: 200$ & HIER, pH 6 \\
\hline NER & $\begin{array}{l}\text { XPA (DNA repair protein } \\
\text { complementing XP-A cells) }\end{array}$ & $\begin{array}{l}\text { Mouse monoclonal (12F5)/ } \\
\text { ThermoFisher MA5-13835 }\end{array}$ & $1: 100$ & HIER, pH 6 \\
\hline MMR & MLH1 (MutL protein homolog 1) & $\begin{array}{l}\text { Rabbit monoclonal/ } \\
\text { Abcam ab92312 }\end{array}$ & $1: 100$ & HIER, pH 6 \\
\hline SSBR & $\begin{array}{c}\text { PARP1 [Poly (ADP-ribose) } \\
\text { polymerase 1] }\end{array}$ & $\begin{array}{c}\text { Mouse monoclonal/Sigma } \\
\text { Precision Plus AMAb90960 }\end{array}$ & $1: 7,500$ & HIER, pH 6 \\
\hline DSBR (NHEJ) & $\begin{array}{c}\text { XRCC6 (X-ray repair } \\
\text { cross-complementing protein 6) }\end{array}$ & $\begin{array}{c}\text { Rabbit polyclonal/ } \\
\text { Sigma Precision Plus } \\
\text { HPA062226 }\end{array}$ & $1: 50$ & HIER, pH 6 \\
\hline \multicolumn{5}{|c|}{ Oxidative/nitrosative stress } \\
\hline Oxidative stress & 4-HNE (4-hydroxy-2-nonenal) & Rabbit polyclonal/Abcam ab46545 & $1: 800$ & HIER, pH 6 \\
\hline Nitrosative stress & 3-NT (3-nitrotyrosine) & Rabbit polyclonal/Sigma AB5411 & $1: 500$ & HIER, pH 6 \\
\hline
\end{tabular}

HIER: Heat-induced epitope retrieval.

virtually all epithelial cells were positive for these markers. Intensity was scored as 0 (negative), 1 (weak), 2 (moderate) or 3 (strong) for comparative purposes.

Statistical analyses. GraphPad Prism version 9 (GraphPad Software, La Jolla, CA) was used for statistical analyses. Non-parametric oneway ANOVA testing (Kruskal-Wallis) was used to assess differences between the median percentages of protein expression within each patient group (colonic mucosa, UC, CRC). Spearman non-parametric correlation analyses were used to test for relationships among the different protein expressions in CRC and UC, and between protein expression levels and clinicopathological features (age, gender, Dukes' stage and tumor site) in CRC. For the purposes of comparison, expression data for NUCKS1 and $\mathrm{pH} 2 \mathrm{AX}$ from our previous report (7) were analyzed for correlations with DNA repair protein expressions in the present study. A $p$-value of $<0.05$ denoted statistical significance.

\section{Results}

Localization of antibodies. Antibodies against OGG1, XPA, MLH1, PARP1, and XRCC6 were localized to the nucleus of epithelial cells in normal colonic mucosa, UC, and CRC biopsies (Figures 1 and 2). Nuclei of infiltrating leucocytes in both UC and CRC biopsies also showed positivity for these antibodies and were excluded from QuPath analyses. Negative staining controls showed no staining for any of the antibodies tested; tonsil tissue was used as a positive staining control for all antibodies. Antibodies against 4-HNE and 3-NT were localized to the cytoplasm of epithelial cells in the majority of normal colonic mucosa, UC, and CRC biopsies (Figure 2). In some cases, both nuclear and cytoplasmic staining was seen.

DNA repair protein expression levels. Figure 3 presents box plots showing the expression levels (median percentage positivity) for each DNA repair protein investigated in normal mucosa, UC, and CRC. Table II summarizes the statistical differences between each patient group for DNA repair protein expression. All DNA repair proteins studied had significantly higher levels of expression in UC and CRC biopsies than in normal colonic mucosa. DNA repair protein expression differed significantly between UC and CRC biopsies. XPA and XRCC6 were significantly higher in UC than in CRC, whereas MLH1 and PARP1 were significantly higher in CRC than in UC. OGG1 levels were similar in both $\mathrm{UC}$ and CRC.

Correlations between different DNA repair proteins and between DNA repair proteins and clinicopathological parameters. XRCC6 expression was positively correlated with XPA expression $(\mathrm{r}=0.38, p=0.002)$ and MLH1 expression ( $\mathrm{r}=0.35, p=0.006)$ in UC but not in CRC. XRCC6 expression was inversely correlated with $\mathrm{pH} 2 \mathrm{AX}$ expression $(\mathrm{r}=-0.35$, $p=0.01)$ in CRC but no correlations were seen between the same in UC. XRCC6 expression was positively correlated with NUCKS 1 expression in CRC $(\mathrm{r}=0.48, p=0.0003)$ and in $\mathrm{UC}(\mathrm{r}=0.42, p=0.005)$. There were no correlations between the individual DNA repair protein expression in CRC and age, gender, Dukes' stage, or histology.

Staining intensities of 4-HNE and 3-NT. The majority (79\%) of normal mucosa were weakly-stained for 4 -HNE, $16 \%$ were negative and 5\% were moderately-stained. All UC biopsies showed 4-HNE staining of various degrees of intensity: $17 \%$ were weakly-stained, $42 \%$ were moderately stained and $41 \%$ were strongly stained for 4-HNE. All CRC biopsies showed $4 \mathrm{HNE}$ staining of various degrees of 
OGG1
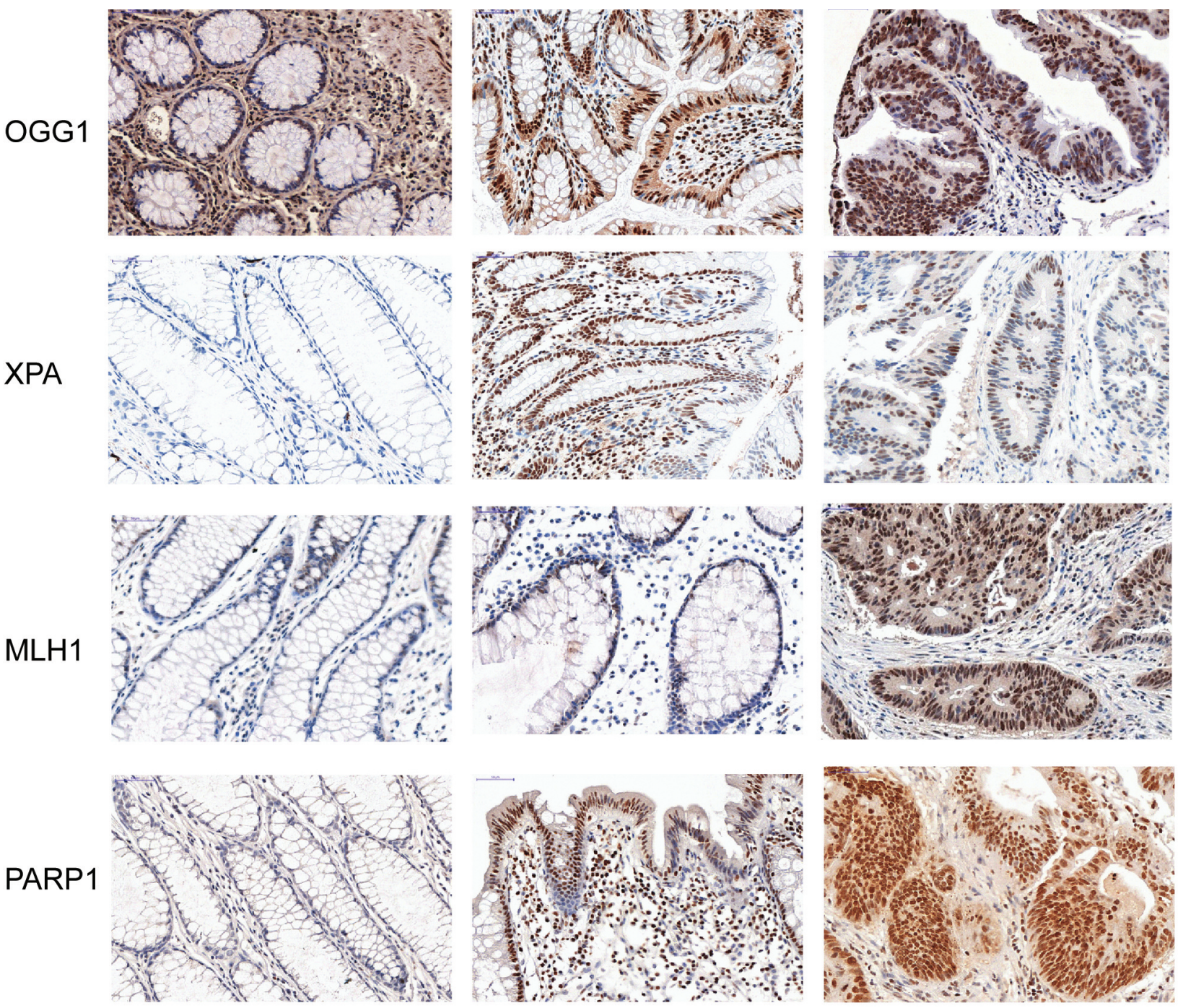

Figure 1. Expression of DNA repair proteins OGG1,XPA, MLH1 and PARP1 in colonic mucosa, ulcerative colitis, and colorectal cancer. 400x magnification. Scale bar $=50 \mu \mathrm{m}$.

intensity: $19 \%$ were weakly stained, $51 \%$ were moderately stained and $30 \%$ were strongly stained for 4-HNE.The majority $(60 \%)$ of normal mucosa were weakly-stained for $3-\mathrm{NT}, 3 \%$ were negative, and $37 \%$ were moderately-stained. All UC biopsies showed 3-NT staining of various degrees of intensity: $2 \%$ were weakly stained, $62 \%$ were moderately stained and $36 \%$ were strongly stained. In CRC, $8 \%$ were weakly stained for 3-NT, $27 \%$ were moderately stained and $65 \%$ were strongly stained.

\section{Discussion}

All the DNA repair proteins evaluated in the present study had significantly higher levels of expression in UC and CRC biopsies than in normal colonic mucosa, suggesting that DNA repair activity is higher in diseased colonic tissue than in (presumably) healthy colonic tissue. In the case of UC, most DNA damage is likely to be due to elevated levels of oxidative stress caused by chronic inflammation, thus BER, NER and SSBR will play important roles in removing the base alterations, abasic sites, or strand breaks that result. BER is an important first line of defense against the mutagenic effects of oxidative DNA damage. One of the most common products of oxidative stress is the base lesion 8-oxo-2'-deoxyguanosine (8oxo-dG), which commonly induces GC to TA transversion mutations (14). The BER enzymes MUTYH, OGG1, and MTH1 work together to repair oxidative DNA damage, but OGG1 is the primary enzyme responsible for the excision of 
Normal mucosa
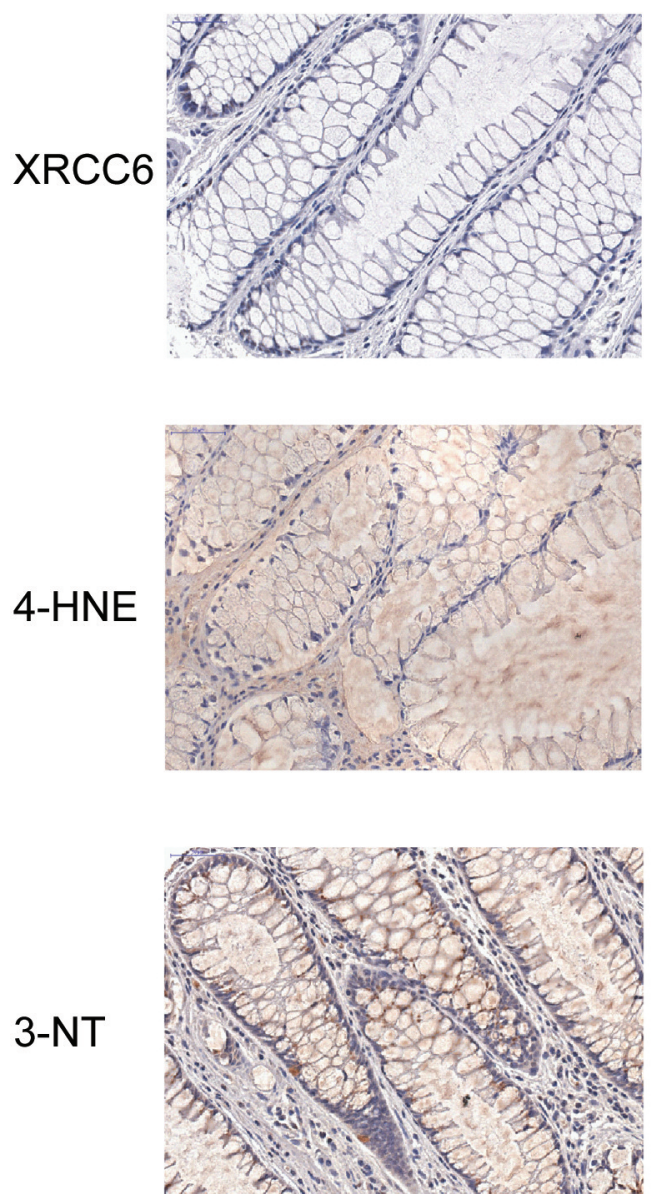

UC
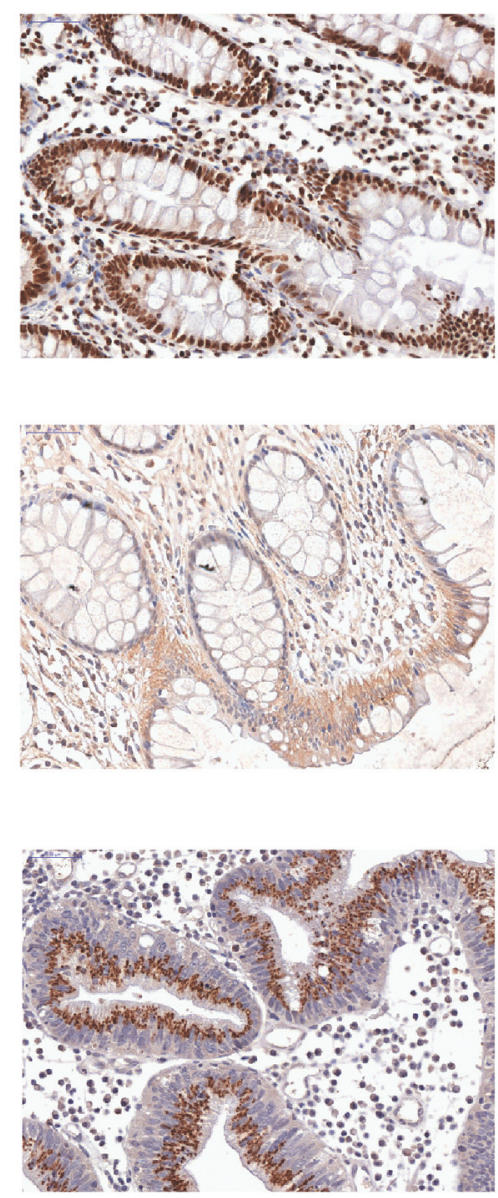

CRC
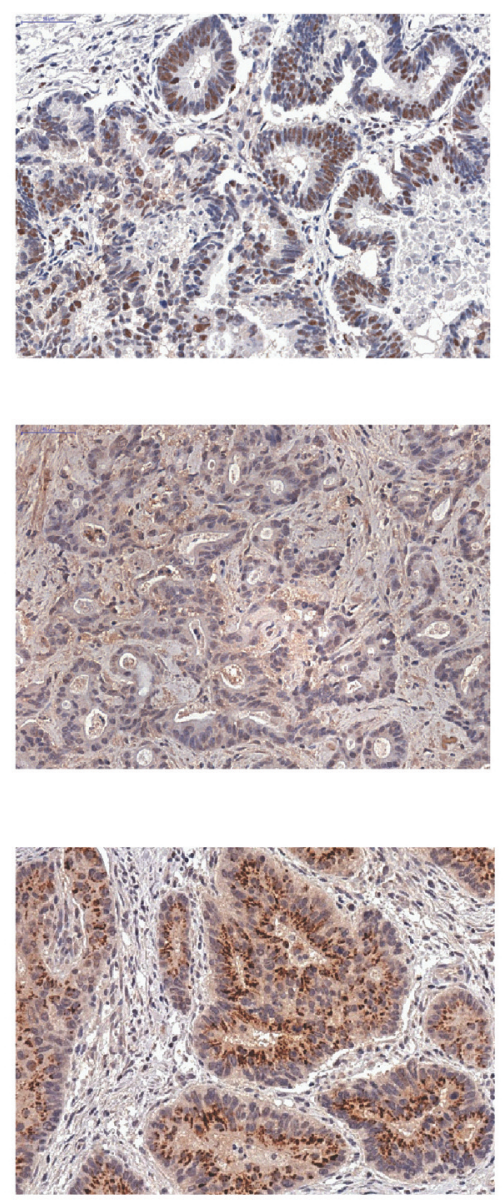

Figure 2. Expression of DNA repair protein XRCC6 and oxidative/nitrosative stress markers in colonic mucosa, ulcerative colitis, and colorectal cancer. $400 \times$ magnification. Scale bar $=50 \mu \mathrm{m}$.

Table II. p-Values showing differences in DNA repair protein expression between normal mucosa, UC, and CRC groups.

\begin{tabular}{lcccc}
\hline DNA repair protein & UC versus normal mucosa & CRC versus normal mucosa & UC versus CRC & UC non-dysplasia versus dysplasia* \\
\hline OGG1 & $<0.0001$ & $<0.0001$ & 0.65 & 0.8 \\
XPA & $<0.0001$ & $<0.0004$ & $<0.0001$ & 0.4 \\
MLH1 & 0.0027 & $<0.0001$ & $<0.0001$ & 0.8 \\
PARP1 & $<0.0001$ & $<0.0001$ & 0.01 & 0.97 \\
XRCC6 & $<0.0001$ & $<0.0001$ & $<0.0001$ & 0.4 \\
\hline
\end{tabular}

UC: Ulcerative colitis; CRC: colorectal carcinoma. $p<0.05$ denotes statistical significance. $*$ Colitis-associated cancers were excluded from the UC dysplasia group in all statistical analyses.

8-oxo-dG. Loss of functional OGG1 activity/OGG1 deficiency in murine models has been reported to lead to a five-fold increase in 8-oxo-dG levels in mouse livers compared to mice with wild-type OGG1 and an increased risk of cancer $(15,16)$.
Likewise, a previous study underscored the importance of MUTYH's role in removing 8-oxo-dG and in the prevention of cancer by showing that defects in MUTYH were associated with the development of CRC (17). 8-oxo-dG levels of normal 
colonic mucosa not undergoing colorectal tumorigenesis were shown to be low in a murine model (18), and it might be expected that the same would be true for normal human colonic mucosa. However, OGG1 levels in normal colonic mucosa in the present work were high (indicating elevated OGG1 activity due to high 8-oxo-dG levels), likely due to the fact that all normal colonic mucosa included in the study were colectomy specimens from operated colorectal cancer patients, and as such were exposed to the same oxidative stress levels as the tumors that also had high OGG1 levels. Furthermore, it is known that 8-oxo-dG levels in DNA increase with age (19), which may be an additional explanation for high OGG1 levels seen in normal colonic mucosa, since colorectal cancer patients in the present study were of advanced age (mean of 69 years). Interestingly, BER is deregulated by 4-HNE in a cell line model exposed to oxidative and alkylating agents, leading to an increase in SSB (9), but judging by the high levels of OGG1 in UC and CRC in the present work, BER does not appear to be compromised in either disease.

NER is also involved in the repair of oxidative stressinduced DNA damage $(20,21)$. Levels of XPA, a key NER protein, were significantly elevated in UC compared to $\mathrm{CRC}$ and normal colonic mucosa, suggesting that oxidative/ nitrosative stress-induced DNA damage requiring NER activity is higher in UC than in CRC or normal mucosa, or that NER is compromised in CRC despite similar levels of oxidative/nitrosative stress. The XPA protein recognizes and binds to damaged DNA, playing a key role as a scaffold protein in NER (22); it binds other NER proteins involved in damage recognition and gap-filling synthesis, as well as proteins not directly involved in NER, such as PARP1. Interestingly, XPA stimulates PARP1 activity (23), but our study showed no correlation (positive or negative) between XPA and PARP expression in either UC or CRC. PARP1 is also responsible for the PARylation of XPA (24), which reduces the DNA binding activity of XPA. It could be speculated that the elevated PARP1 levels in both UC and CRC affected the DNA binding capacity of XPA, but we have not investigated this. 4-HNE hindered NER in lung and colon cancer cell lines (25), which could be one explanation for the comparatively lower XPA levels in CRC than in UC, but this remains hypothetical in the context of our study.

MMR did not appear to be compromised in either UC or CRC; the highest MLH1 levels were seen in CRC, although levels were also high in UC. The majority of normal colonic mucosa biopsies also expressed moderate levels of MLH1, indicating that DNA MMR is important in (presumably) normal cells. MMR is critical for ensuring the fidelity of DNA replication during DNA synthesis; if misincorporated (mismatched) bases are not removed, this can lead to mutations during the next round of replication. Our MLH1 data for sporadic CRC are in agreement with the study of Lanza et al. (26) that reported that MSI-L and MSS colorectal tumors had normal expression of MLH1 protein, whereas MSI-H tumors showed loss of protein expression due to MLH1 mutation. Although we have not determined the microsatellite instability status for the sporadic CRC in the present work, they are most likely MSS, because our earlier comparative genomic hybridization study of sporadic CRC (27) indicated that the majority of them were characterized by chromosomal instability. Thus, it might be expected that the majority of them would express moderate to elevated levels of MLH1. Likewise, MLH1 levels were high in UC in the present work; again, we have not determined UC microsatellite instability status. However, a previous report showed that loss of MLH1 expression was rare in colitis-associated colorectal cancer (28), indicating that MLH1 expression in UC is generally not compromised, consistent with our results.

PARP1 is the main PARP enzyme in the PARP family of proteins that is involved early on in the cellular DNA damage response. Its ability to detect DNA strand breaks, to modulate chromatin structure, and interact with and modify many DNA repair factors facilitates the choice of DNA repair pathway in response to DNA damage (29). Although PARP1 was first reported to play a role in SSBR and BER (29-31), later reports indicate important roles for PARP1 in all DNA repair pathways as well as in genome maintenance (29, 32-35). PARP1 can also promote inflammatory responses by positively regulating pro-inflammatory NF- $x \mathrm{~B}$ transcription factors (36). PARP1 levels were high in UC and CRC (levels in normal colonic mucosa were generally very low) in the present work. Our PARP1 data for CRC are consistent with previous reports of PARP1 overexpression in CRC (37-40). The high PARP1 levels seen in CRC may indicate an attempt to maintain genomic stability via involvement in multiple DNA repair pathways. The high PARP1 levels seen in UC are more likely indicative of PARP1 activation and elevated expression in response to oxidative stress-induced inflammation leading to further generation of RONS $(36,39)$. It remains unclear whether DNA repair activity is compromised in UC, despite the high PARP1 levels seen. PARP1 expression was not correlated with the expression of other DNA repair proteins in either CRC or UC. The high PARP1 levels seen in both diseases could open for targeted treatment of affected patients with PARP1 inhibitors as a potential treatment modality, especially since PARP1 plays important roles in all DNA repair pathways.

We previously reported that the HR DSBR protein NUCKS1 decreased with increasing grades of UC dysplasia, and was lowest in CRC samples, whereas expression of the DNA DSB marker $\mathrm{pH} 2 \mathrm{AX}$ increased with increasing grades of UC dysplasia and was highest in CRC (7). It was suggested that HR DSBR was perhaps impaired in dysplastic UC and in cancer, leading to an increase in DSBs. 
a

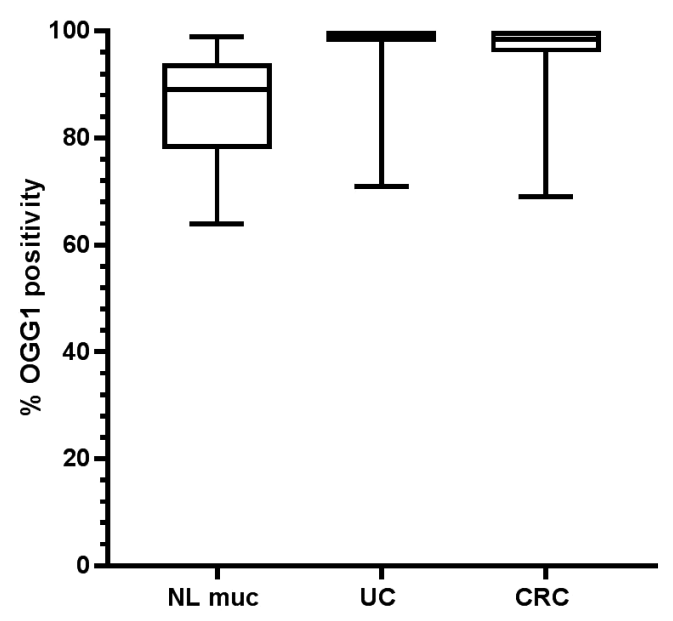

C

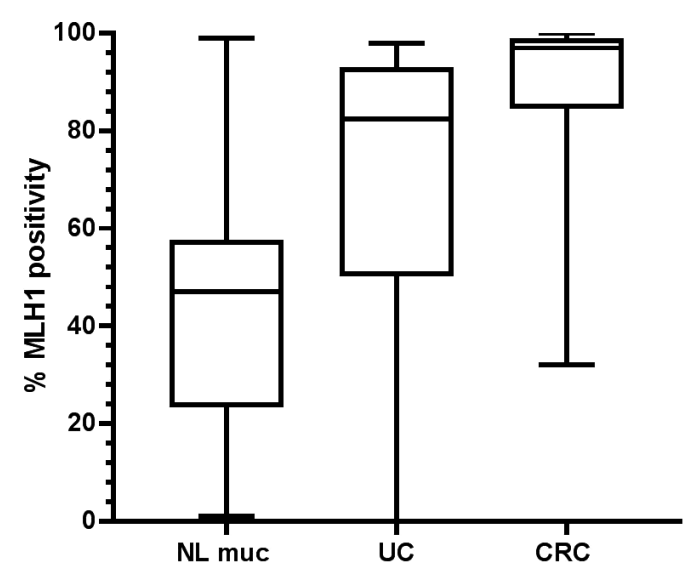

e

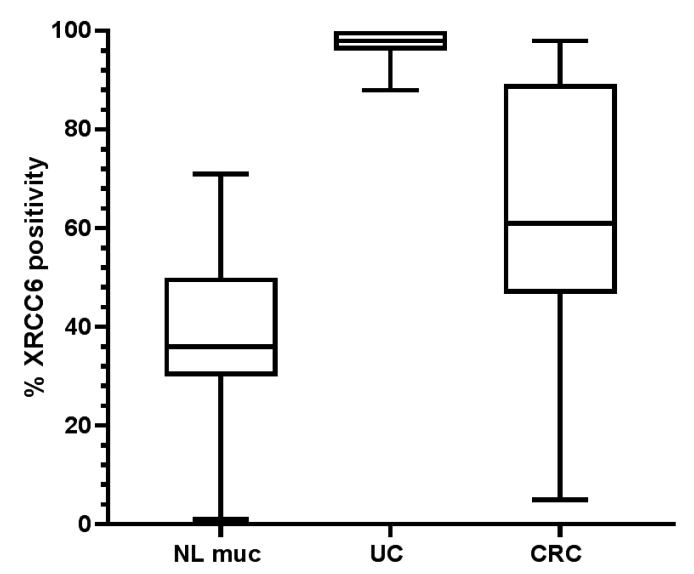

b

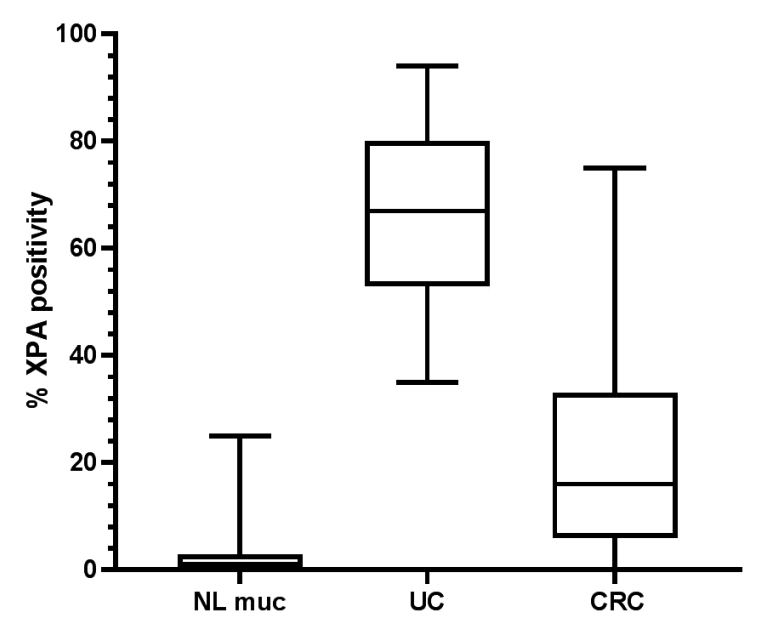

d

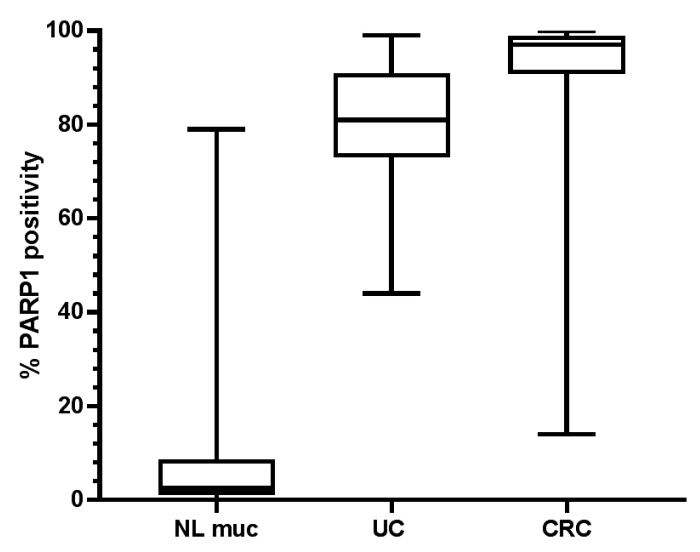

Figure 3. DNA repair protein expression levels in colonic mucosa, ulcerative colitis, and colorectal cancer. 
Alternatively, the increase in DSBs could have overwhelmed the available HR DSBR capacity. Our results were, however, complicated by the fact that NUCKS1 is also involved in inflammatory signaling, and that the high NUCKS1 levels seen in UC could have been due to the high levels of inflammation in UC (7). Interestingly, the pattern of expression of XRCC6, which plays a role in NHEJ DSBR, tended to be similar to that seen for NUCKS1 - a significant decrease in expression in sporadic CRC compared to UC [concomitant with an increase in DSBs in CRC (7)]. Furthermore, XRCC6, besides its role in NHEJ, is also required for telomere length maintenance and sub-telomeric gene silencing (41). One interesting question is whether lower XRCC6 expression in CRC could reflect the problematic telomere shortening that is characteristic of CRC and many other cancer types. UC had very low levels of DSBs (7) and very high expression of XRCC6, suggesting that NHEJ DSBR is not compromised in UC. Based on the results of the present study and our previous work (7), DNA DSBR (both NHEJ and HR) seem to be compromised in CRC but not in UC.

Both UC and CRC biopsies had moderate to high expression of 4-HNE and 3-NT, indicating similar levels of oxidative/nitrosative stress in both diseases. High 4-HNE levels in CRC have been reported previously $(42,43)$. Interestingly, besides damaging DNA directly, 4-HNE also inhibits DNA repair mechanisms, specifically NER following UV light irradiation in human colon and lung epithelial cells, which may contribute to carcinogenesis (25). Since 4-HNE levels were similarly elevated in both UC and CRC in the present work, one might question whether this would impact on NER in both diseases. Interestingly, XPA expression was very high in UC whereas a four-fold reduction in expression was seen in CRC compared to UC, suggesting that NER could be compromised in CRC. However, since we have not investigated expression levels of other proteins involved in NER, this remains hypothetical. High levels of 3-NT were previously observed in colitis and cancer $(44,45)$ as well as in the plasma of patients with celiac disease (an inflammatory disease of the small intestine) (46), indicating an association between inflamed tissues and nitrosative stress. Our results for 3-NT expression in UC and CRC are consistent with these earlier reports. Normal colonic mucosa had low levels of both 4-HNE and 3-NT compared to UC and $\mathrm{CRC}$, indicating that there is less oxidative/nitrosative stress in normal colonic tissue than in diseased. At moderate or high concentrations RONS are harmful due to their ability to alter DNA, proteins and lipids via oxidative damage; however, at low concentrations they play an important role as regulatory intermediaries in signaling processes (47). The specific concentrations at which RONS become detrimental for cells are however not known. The low levels of 4-HNE and 3-NT seen in normal colonic mucosa are consistent with low concentrations of RONS being associated with normal signaling processes in normal tissues.

In conclusion, we showed that oxidative/nitrosative stress is prevalent in the colons of UC and CRC patients and that nucleotide excision repair and non-homologous end-joining double-strand break repair (exemplified by XPA and XRCC6 expression, respectively) may be compromised in CRC but not in UC. PARP1 is reported to promote inflammatory responses; in UC, where the chronic inflammation can predispose to colorectal cancer, high levels of PARP1 could play a role in progression to cancer. The high PARP1 levels seen in CRC, where genomic instability and DNA damage are prevalent, suggest that it plays an important role in repairing this extensive DNA damage via its involvement on multiple DNA repair pathways. Overall, the high PARP1 levels seen in both diseases could open for potential targeted treatment of affected patients with PARP1 inhibitors. It would not be feasible to use any of the DNA repair proteins studied as diagnostic biomarkers of CRC because none of them showed correlations with clinicopathological parameters such as age, gender, Dukes' stage, or histology. However, from a pathobiological standpoint, reduced expression of proteins involved in double-strand break repair (both homologous recombination and non-homologous end-joining), concomitant with high levels of double-strand breaks, may lead to tumor development. Genomic instability and cancer are the likely results of DNA double-strand break repair that is compromised or overwhelmed by oxidative/nitrosative stress-induced DNA damage.

\section{Conflicts of Interest}

The Authors declare no conflicts of interest in connection with this manuscript.

\section{Authors' Contributions}

PMD conceived and designed the study, analyzed and interpreted the data, and wrote the manuscript. LD performed the immunohistochemical stainings, slide scanning, and QuPath countings. SP performed the PARP1 immunohistochemical staining and counting. SNA performed the pathological evaluations of the ulcerative colitis biopsies. All Authors reviewed and approved the final version of the manuscript.

\section{Acknowledgements}

This study was supported by a generous grant from the Oslo University Hospital Research Fund Foundation (2019-04).

\section{References}

1 Sies H: Oxidative stress: Concept and some practical aspects. Antioxidants (Basel) 9(9): 2020. PMID: 32927924. DOI: 10.3390/antiox 9090852 
2 Sies H, Berndt $\mathrm{C}$ and Jones DP: Oxidative stress. Annu Rev Biochem 86: 715-748, 2017. PMID: 28441057. DOI: 10.1146/annurev-biochem-061516-045037

3 Melis JP, van Steeg H and Luijten M: Oxidative DNA damage and nucleotide excision repair. Antioxid Redox Signal 18(18): 24092419, 2013. PMID: 23216312. DOI: 10.1089/ars.2012.5036

4 Gentile F, Arcaro A, Pizzimenti S, Daga M, Cetrangolo GP, Dianzani C, Lepore A, Graf M, Ames PRJ and Barrera G: DNA damage by lipid peroxidation products: implications in cancer, inflammation and autoimmunity. AIMS Genet 4(2): 103-137, 2017. PMID: 31435505. DOI: 10.3934/genet.2017.2.103

5 Ahsan H: 3-Nitrotyrosine: A biomarker of nitrogen free radical species modified proteins in systemic autoimmunogenic conditions. Hum Immunol 74(10): 1392-1399, 2013. PMID: 23777924. DOI: 10.1016/j.humimm.2013.06.009

6 Kidane D, Chae WJ, Czochor J, Eckert KA, Glazer PM, Bothwell AL and Sweasy JB: Interplay between DNA repair and inflammation, and the link to cancer. Crit Rev Biochem Mol Biol 49(2): 116-139, 2014. PMID: 24410153. DOI: 10.3109/ 10409238.2013.875514

7 De Angelis PM, Schjølberg AR, Hughes JB, Huitfeldt HS, Norheim Andersen S and Østvold AC: Nondysplastic ulcerative colitis has high levels of the homologous recombination repair protein NUCKS1 and low levels of the DNA damage marker gamma-H2AX. Inflamm Bowel Dis 24(3): 593-600, 2018. PMID: 29462394. DOI: 10.1093/ibd/izx071

8 Teixeira D, Fernandes R, Prudêncio C and Vieira M: 3Nitrotyrosine quantification methods: Current concepts and future challenges. Biochimie 125: 1-11, 2016. PMID: 26921794. DOI: $10.1016 / \mathrm{j}$. biochi.2016.02.011

9 Winczura A, Czubaty A, Winczura K, Masłowska K, Nałęcz M, Dudzińska DA, Saparbaev M, Staroń K and Tudek B: Lipid peroxidation product 4-hydroxy-2-nonenal modulates base excision repair in human cells. DNA Repair (Amst) 22: 1-11, 2014. PMID: 25083554. DOI: 10.1016/j.dnarep. 2014.06.002

10 Riddell RH, Goldman H, Ransohoff DF, Appelman HD, Fenoglio CM, Haggitt RC, Ahren C, Correa P, Hamilton SR and Morson BC: Dysplasia in inflammatory bowel disease: standardized classification with provisional clinical applications Hum Pathol 14(11): 931-968, 1983. PMID: 6629368. DOI: 10.1016/s0046-8177(83)80175-0

11 Burum-Auensen E, Deangelis PM, Schjølberg AR, Røislien J, Andersen SN and Clausen OP: Spindle proteins Aurora A and BUB1B, but not Mad2, are aberrantly expressed in dysplastic mucosa of patients with longstanding ulcerative colitis. J Clin Pathol 60(12): 1403-1408, 2007. PMID: 17322345. DOI: 10.1136/jcp.2006.044305

12 Bankhead P, Loughrey MB, Fernández JA, Dombrowski Y, McArt DG, Dunne PD, McQuaid S, Gray RT, Murray LJ, Coleman HG, James JA, Salto-Tellez M and Hamilton PW: QuPath: Open source software for digital pathology image analysis. Sci Rep 7(1): 16878, 2017. PMID: 29203879. DOI: 10.1038/s41598-017-17204-5

13 Loughrey MB, Bankhead P, Coleman HG, Hagan RS, Craig S, McCorry AMB, Gray RT, McQuaid S, Dunne PD, Hamilton PW, James JA and Salto-Tellez M: Validation of the systematic scoring of immunohistochemically stained tumour tissue microarrays using QuPath digital image analysis. Histopathology 73(2): 327338, 2018. PMID: 29575153. DOI: 10.1111/his.13516
14 Yasui M, Kanemaru Y, Kamoshita N, Suzuki T, Arakawa T and Honma M: Tracing the fates of site-specifically introduced DNA adducts in the human genome. DNA Repair (Amst) 15: 11-20, 2014. PMID: 24559511. DOI: 10.1016/j.dnarep.2014.01.003

15 Liao J, Seril DN, Lu GG, Zhang M, Toyokuni S, Yang AL and Yang GY: Increased susceptibility of chronic ulcerative colitisinduced carcinoma development in DNA repair enzyme Ogg1 deficient mice. Mol Carcinog 47(8): 638-646, 2008. PMID: 18300266. DOI: $10.1002 / \mathrm{mc} .20427$

16 Sakumi K, Tominaga Y, Furuichi M, Xu P, Tsuzuki T, Sekiguchi $M$ and Nakabeppu Y: Ogg1 knockout-associated lung tumorigenesis and its suppression by Mth1 gene disruption. Cancer Res 63(5): 902-905, 2003. PMID: 12615700.

17 Al-Tassan N, Chmiel NH, Maynard J, Fleming N, Livingston AL, Williams GT, Hodges AK, Davies DR, David SS, Sampson JR and Cheadle JP: Inherited variants of MYH associated with somatic G:C $\rightarrow$ T:A mutations in colorectal tumors. Nat Genet 30(2): 227-232, 2002. PMID: 11818965. DOI: 10.1038/ng828

18 Prasad AR, Prasad S, Nguyen H, Facista A, Lewis C, Zaitlin B, Bernstein $\mathrm{H}$ and Bernstein $\mathrm{C}$ : Novel diet-related mouse model of colon cancer parallels human colon cancer. World J Gastrointest Oncol 6(7): 225-243, 2014. PMID: 25024814. DOI: 10.4251/wjgo.v6.i7.225

19 Nie B, Gan W, Shi F, Hu GX, Chen LG, Hayakawa H, Sekiguchi $\mathrm{M}$ and Cai JP: Age-dependent accumulation of 8-oxoguanine in the DNA and RNA in various rat tissues. Oxid Med Cell Longev 2013: 303181, 2013. PMID: 23738036. DOI: $10.1155 / 2013 / 303181$

20 Berquist BR and Wilson DM 3rd: Pathways for repairing and tolerating the spectrum of oxidative DNA lesions. Cancer Lett 327(1-2): 61-72, 2012. PMID: 22353689. DOI: 10.1016/ j.canlet.2012.02.001

21 Slupphaug G, Kavli B and Krokan HE: The interacting pathways for prevention and repair of oxidative DNA damage. Mutat Res 531(1-2): 231-251, 2003. PMID: 14637258. DOI: 10.1016/ j.mrfmmm.2003.06.002

22 Sugitani N, Sivley RM, Perry KE, Capra JA and Chazin WJ: XPA: A key scaffold for human nucleotide excision repair. DNA Repair (Amst) 44: 123-135, 2016. PMID: 27247238. DOI: 10.1016/j.dnarep.2016.05.018

23 Fischer JM, Popp O, Gebhard D, Veith S, Fischbach A, Beneke S, Leitenstorfer A, Bergemann J, Scheffner M, Ferrando-May E, Mangerich A and Bürkle A: Poly(ADP-ribose)-mediated interplay of XPA and PARP1 leads to reciprocal regulation of protein function. FEBS J 281(16): 3625-3641, 2014. PMID: 24953096. DOI: 10.1111/febs.12885

24 Borszéková Pulzová L, Ward TA and Chovanec M: XPA: DNA repair protein of significant clinical importance. Int J Mol Sci 21(6): 2182, 2020. PMID: 32235701. DOI: 10.3390/ijms 21062182

25 Feng Z, Hu W and Tang MS: Trans-4-hydroxy-2-nonenal inhibits nucleotide excision repair in human cells: a possible mechanism for lipid peroxidation-induced carcinogenesis. Proc Natl Acad Sci USA 101(23): 8598-8602, 2004. PMID: 15187227. DOI: $10.1073 /$ pnas.0402794101

26 Lanza G, Gafà R, Maestri I, Santini A, Matteuzzi M and Cavazzini L: Immunohistochemical pattern of MLH1/MSH2 expression is related to clinical and pathological features in colorectal adenocarcinomas with microsatellite instability. Mod Pathol 15(7): 741-749, 2002. PMID: 12118112. DOI: 10.1097/ 01.MP.0000018979.68686.B2 
27 De Angelis PM, Clausen OP, Schjølberg A and Stokke T: Chromosomal gains and losses in primary colorectal carcinomas detected by $\mathrm{CGH}$ and their associations with tumour DNA ploidy, genotypes and phenotypes. Br J Cancer 80(3-4): 526-535, 1999. PMID: 10408863 . DOI: $10.1038 /$ sj.bjc.6690388

28 Cawkwell L, Sutherland F, Murgatroyd H, Jarvis P, Gray S, Cross D, Shepherd N, Day D and Quirke P: Defective $\mathrm{hMSH} 2 / \mathrm{hMLH} 1$ protein expression is seen infrequently in ulcerative colitis associated colorectal cancers. Gut 46(3): 367369, 2000. PMID: 10673298. DOI: 10.1136/gut.46.3.367

29 Pascal JM: The comings and goings of PARP-1 in response to DNA damage. DNA Repair (Amst) 71: 177-182, 2018. PMID: 30177435. DOI: 10.1016/j.dnarep.2018.08.022

30 Dantzer F, de La Rubia G, Ménissier-De Murcia J, Hostomsky $\mathrm{Z}$, de Murcia $\mathrm{G}$ and Schreiber V: Base excision repair is impaired in mammalian cells lacking Poly(ADP-ribose) polymerase-1. Biochemistry 39(25): 7559-7569, 2000. PMID: 10858306. DOI: $10.1021 / \mathrm{bi0003442}$

31 Fisher AE, Hochegger $\mathrm{H}$, Takeda $\mathrm{S}$ and Caldecott KW: Poly(ADP-ribose) polymerase 1 accelerates single-strand break repair in concert with poly(ADP-ribose) glycohydrolase. Mol Cell Biol 27(15): 5597-5605, 2007. PMID: 17548475. DOI: 10.1128/MCB.02248-06

$32 \mathrm{Hu}$ Y, Petit SA, Ficarro SB, Toomire KJ, Xie A, Lim E, Cao SA, Park E, Eck MJ, Scully R, Brown M, Marto JA and Livingston DM: PARP1-driven poly-ADP-ribosylation regulates BRCA1 function in homologous recombination-mediated DNA repair. Cancer Discov 4(12): 1430-1447, 2014. PMID: 25252691. DOI: 10.1158/2159-8290.CD-13-0891

33 Liu Y, Kadyrov FA and Modrich P: PARP-1 enhances the mismatch-dependence of 5'-directed excision in human mismatch repair in vitro. DNA Repair (Amst) 10(11): 1145-1153, 2011. PMID: 21945626. DOI: 10.1016/j.dnarep.2011.08.012

34 Luijsterburg MS, de Krijger I, Wiegant WW, Shah RG, Smeenk G, de Groot AJL, Pines A, Vertegaal ACO, Jacobs JJL, Shah GM and van Attikum H: PARP1 links CHD2-mediated chromatin expansion and $\mathrm{H} 3.3$ deposition to DNA repair by nonhomologous end-joining. Mol Cell 61(4): 547-562, 2016. PMID: 26895424. DOI: 10.1016/j.molcel.2016.01.019

35 Pines A, Vrouwe MG, Marteijn JA, Typas D, Luijsterburg MS, Cansoy M, Hensbergen P, Deelder A, de Groot A, Matsumoto S, Sugasawa K, Thoma N, Vermeulen W, Vrieling $\mathrm{H}$ and Mullenders L: PARP1 promotes nucleotide excision repair through DDB2 stabilization and recruitment of ALC1. J Cell Biol 199(2): 235-249, 2012. PMID: 23045548. DOI: $10.1083 /$ jcb.201112132

36 Pazzaglia S and Pioli C: Multifaceted role of PARP-1 in DNA repair and inflammation: Pathological and therapeutic implications in cancer and non-cancer diseases. Cells 9(1): , 2019. PMID: 31877876. DOI: 10.3390/cells9010041

37 Dziaman T, Ludwiczak H, Ciesla JM, Banaszkiewicz Z, Winczura A, Chmielarczyk M, Wisniewska E, Marszalek A, Tudek B and Olinski R: PARP-1 expression is increased in colon adenoma and carcinoma and correlates with OGG1. PLoS One 9(12): e115558, 2014. PMID: 25526641. DOI: 10.1371/journal.pone.0115558
38 Nosho K, Yamamoto H, Mikami M, Taniguchi H, Takahashi T, Adachi Y, Imamura A, Imai K and Shinomura Y: Overexpression of poly(ADP-ribose) polymerase-1 (PARP-1) in the early stage of colorectal carcinogenesis. Eur J Cancer 42(14): 2374-2381, 2006. PMID: 16809031. DOI: 10.1016/j.ejca.2006.01.061

39 Dörsam B, Seiwert N, Foersch S, Stroh S, Nagel G, Begaliew D, Diehl E, Kraus A, McKeague M, Minneker V, Roukos V, Reißig S, Waisman A, Moehler M, Stier A, Mangerich A, Dantzer F, Kaina B and Fahrer J: PARP-1 protects against colorectal tumor induction, but promotes inflammation-driven colorectal tumor progression. Proc Natl Acad Sci USA 115(17): E4061-E4070, 2018. PMID: 29632181. DOI: 10.1073/pnas.1712345115

40 Pham S: Ekspresjon av DNA-reparasjonsprotein PARP1 i ulcerøs kolitt og kolorektalkreft: En immunhistokjemisk studie. Master in Biomedicine, Oslo Met, 2018. Available at: https://oda.oslomet.no/oda-xmlui/handle/10642/8561 [Last accessed on June 14, 2021]

41 Boulton SJ and Jackson SP: Components of the Ku-dependent non-homologous end-joining pathway are involved in telomeric length maintenance and telomeric silencing. EMBO J 17(6): 18191828, 1998. PMID: 9501103. DOI: 10.1093/emboj/17.6.1819

42 Biasi F, Tessitore L, Zanetti D, Cutrin JC, Zingaro B, Chiarpotto E, Zarkovic N, Serviddio G and Poli G: Associated changes of lipid peroxidation and transforming growth factor beta1 levels in human colon cancer during tumour progression. Gut 50(3): 361-367, 2002. PMID: 11839715. DOI: 10.1136/gut.50.3.361

43 Skrzydlewska E, Stankiewicz A, Sulkowska M, Sulkowski S and Kasacka I: Antioxidant status and lipid peroxidation in colorectal cancer. J Toxicol Environ Health A 64(3): 213-222, 2001. PMID: 11594700. DOI: $10.1080 / 15287390152543690$

44 Gochman E, Mahajna J, Shenzer P, Dahan A, Blatt A, Elyakim $\mathrm{R}$ and Reznick AZ: The expression of iNOS and nitrotyrosine in colitis and colon cancer in humans. Acta Histochem 114(8): 827835, 2012. PMID: 22417974. DOI: 10.1016/j.acthis.2012.02.004

45 Kimura H, Hokari R, Miura S, Shigematsu T, Hirokawa M, Akiba Y, Kurose I, Higuchi H, Fujimori H, Tsuzuki Y, Serizawa $\mathrm{H}$ and Ishii $\mathrm{H}$ : Increased expression of an inducible isoform of nitric oxide synthase and the formation of peroxynitrite in colonic mucosa of patients with active ulcerative colitis. Gut 42(2): 180187, 1998. PMID: 9536941. DOI: 10.1136/gut.42.2.180

46 ter Steege JC, Koster-Kamphuis L, van Straaten EA, Forget PP and Buurman WA: Nitrotyrosine in plasma of celiac disease patients as detected by a new sandwich ELISA. Free Radic Biol Med 25(8): 953-963, 1998. PMID: 9840741. DOI: 10.1016/ s0891-5849(98)00184-1

47 Di Meo S, Reed TT, Venditti P and Victor VM: Role of ROS and RNS sources in physiological and pathological conditions. Oxid Med Cell Longev 2016: 1245049, 2016. PMID: 27478531. DOI: 10.1155/2016/1245049

Received May 18, 2021

Revised June 8, 2021

Accepted June 14, 2021 